\title{
PHYSIOLOGY IN PLATO'S TIMAEUS: IRRIGATION, DIGESTION AND RESPIRATION
}

\author{
Andrés Pelavski` \\ Papworth Hospital
}

The third part of the Timaeus, where the account is focused on the cooperation of reason and necessity, has received far less attention than the opening two sections. Particularly, the description of irrigation, digestion and respiration constitutes a challenging passage that has been conspicuously overlooked by scholarly research. Virtually the only modern explanation for the passage was devised by Cornford, and despite several inaccuracies it has been unanimously accepted by all commentators. This paper will challenge Cornford's interpretation, and use some modern biological concepts to provide an alternative approach to the passage more compatible with an actual human body.

In the exegesis of the visible world offered by Timaeus, recent scholarship has given precedence to a rational reading over an aesthetic one: the goal seems to be an intelligible rather than a beautiful world. ${ }^{\mathrm{I}}$ Indeed, our cosmos is regarded as a direct result of the interplay between divine Intelligence and material Necessity. Yet the third part of the account (69a-92c), which deals precisely with the cooperation between Intelligence and Necessity, has received little attention. ${ }^{2}$ This relative lack of interest from philosophers could be explained by the fact that bodily structures and processes within living beings are less 'sexy stuff compared to god, time and space'. ${ }^{3}$ Researchers have mostly investigated how much of the medico-biological account is originally Platonic and how much is borrowed from contemporary or pre-Socratic sources.

Additionally, in this third part of his speech, Timaeus introduces a description of bodily processes which is philologically challenging to 'read and decode'. ${ }^{4}$ The difficulties have prompted various interpretations and criticisms since antiquity. However, none of them

\footnotetext{
* andres.pelavski@nhs.net
}

I would like to thank Dr Myrto Hatzimichali for her guidance when I wrote the first version of this argument, and CCJ's readers for their advice.

I $\operatorname{Mohr}(2010) 7$.

2 Karasmanis (2005) I67.

3 Mohr (2010) I4.

4 Sedley (2010) 246. 
are completely satisfactory. ${ }^{5}$ Most analyses fail to give a coherent account of the corporeal

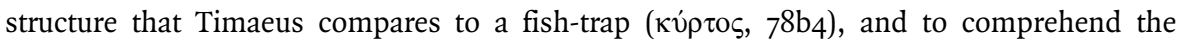
location of its constitutive principles (fire and air). Consequently, the physiological processes where this structure intervenes are also generally misunderstood.

Considering that this section of the dialogue (much like the rest) ${ }^{6}$ is full of descriptive

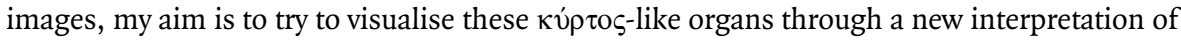
this obscure passage. I shall then attempt an alternative approach to Timaeus' physiology. I shall begin with a general overview of the entire passage, followed by a more detailed discussion of its anatomical components and their physiological correlates. The analysis will also try to clarify how this anatomo-physiological account is seamlessly integrated within the general operation of the cosmos.

\section{Overview of the anatomo-physiological account}

Towards the end of his speech Timaeus discusses the cooperation between Intelligence and Necessity. Having been commissioned to create man, the young gods obediently begin by generating the two parts of the mortal soul and their seats, namely the organs in the thorax and the abdomen respectively $(69 \mathrm{~d}-73 \mathrm{a})$. Subsequently, they create the other parts of the body $\left(73^{b}-76 e\right)$. Once the anatomy is completed, the account focuses on how the organs function, i.e. on physiology. Specifically, the distribution of nourishment, digestion, respiration and the formation of blood are described in relation to the processes of growth, ageing and death. An explanation of disease follows, which is also based on this understanding of the body and the soul (8re-92c).

The entire passage on physiology $(77 \mathrm{c}-8 \mathrm{Ib})$ is constructed in ring-composition, where the anatomical structures and their physiological correlates are organised concentrically, with respiration in the middle. As shown below, Timaeus' description reveals that the anatomical component of each ring is conceived as divinely crafted the works of Intelligence), whereas the physiological component corresponds to the natural behaviour of the elemental particles (the works of Necessity). ${ }^{7}$ In this way, the lesser gods manage, through a carefully designed anatomy, to 'persuade' the simple bodies (fire, air, water and earth) to fulfil their physiological tasks by acting in accordance with their own nature. ${ }^{8}$

The account begins with a description of an 'irrigation' system (77c6-e6) - the set of ducts that enables blood to flow throughout the body. Timaeus uses the image of 'water

5 Examples of ancient comments about this passage include Aristotle's criticism of the respiration process in his De respiratione (472a6-473a2), and Galen's fragmentary In Platonis Timaeum (see Larrain 1992). Among modern scholars, both Taylor (1928) and Cornford addressed this passage. The former was strongly influenced by Galen; the latter (1937, 303-29) offered an explanation which has been almost unanimously accepted despite the problems I shall discuss below.

6 Zeyl (2010) 117.

7 Broadie (2012) 267.

8 Johansen (2004) 99. 
pipes in a garden' to depict the anatomy of the blood vessels: they enable the body to 'be

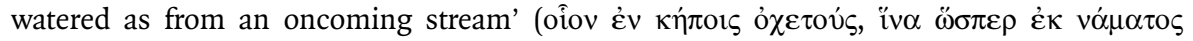

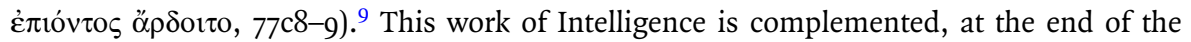
section (80e5-8Ib4), by the distribution of nourishment through the blood vessels, where the gardening similes are picked up to illustrate how the movement of food through the

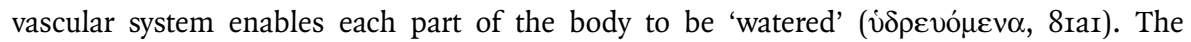
blood is centrifugally driven by one of Necessity's laws of movement: like tends to move towards like (8IaI-4). ${ }^{\text {Io }}$

The second ring deals - in a similar manner - with a prior step, namely the structures and processes that are involved in forming the blood. Accordingly it includes the description of the intelligently crafted organs that are likened to a fish-trap $(77 \mathrm{e} 7-78 \mathrm{~d} 7)$ on the one hand; and the necessary processes of digestion and absorption of food into the blood vessels (78d8-79a5), along with the formation of blood from digested food, and nutrition (8odI-e4) on the other. Finally, at the very heart of the account, Timaeus discusses respiration (79a5-e9).

This discourse about life-conditioning mechanisms is preceded by an excursus, inserted in the midst of the previous anatomical discussion, that tackles the birth of plants $(76 \mathrm{e}-77 \mathrm{c})$, and is followed by an explanation about growth and decay. Plants are the source of nourishment (77c7), and the whole process is conceived in terms of the exchange of nutrients between the world and the body (8Ib5-e6). In other words, the biological account is framed within a further 'environmental' ring, which relates the body to the cosmos.

The present analysis will follow this ring-composition from the periphery to the centre.

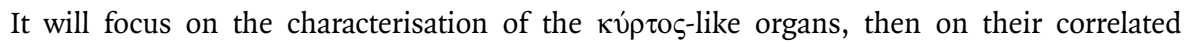
physiological processes (digestion, absorption, formation of blood, nourishment, and finally respiration). I shall not discuss the short digression about phenomena separate from human physiology at $79 e 9-80 c 8 .{ }^{\text {II }}$ Nor shall I address Plato's scientific sources, since they have been extensively studied. ${ }^{12}$

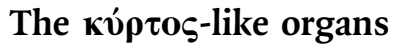

Starting at 77e7, Timaeus offers one of the most fascinating and obscure anatomophysiological explanations in the dialogue. First he enunciates one of Necessity's laws of movement: smaller particles can go through objects made of larger particles, whereas

9 All quotations from Plato's Timaeus follow Rivaud (1970). The translations are my own, based on Zeyl (2000).

Io The term 'circulation', traditionally applied to this passage (e.g. Taylor (I928) 544, Cornford (I937) 303, Mugler (1958) 46), should be used with caution. The blood does not actually circulate, as we nowadays understand the notion. Instead, it simply flows towards the periphery distributing nourishment.

II Taylor (I928) 570 .

I2 Some examples: Taylor (I928, 587-9) emphasises the influence of Philolaos and Empedocles; the latter was disproved by O'Brien (1970) and Hershbell (1974). Mugler (1958, 43) connects Timaeus' account with Alcmaeon; Harris (I973, II7-I9) relates it to Philistion, Joubaud (I99I, 70-3) to Diogenes of Apollonia, Ayache (I997, 55-6) to Diocles and some Hippocratic authors. 
objects made of the former are impermeable to the latter $(78 \mathrm{ar}-\mathrm{b} 2)$. Bearing in mind that fire and air are the smallest elemental particles, Timaeus then asserts:

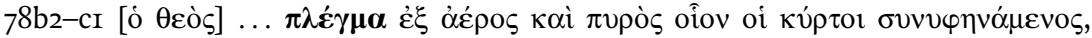

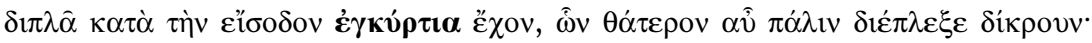

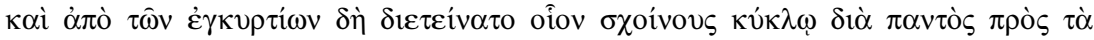

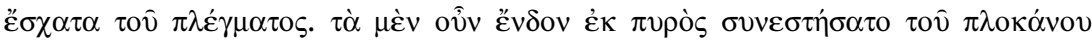

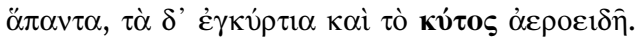

The god ... wove a mesh of air and fire, something like a fish-trap, with dual accesspoints at its entrance, one of which he knitted with a further bifurcation. And from these access-points he stretched something resembling reeds around the mesh all the way through to its extremities. The inner parts of this plaited structure he composed in their entirety of fire, whereas the access-points and the hollow cavity he composed of air.

In order to comprehend this passage in detail, it is useful first to consider the difficulties it presents in the light of current scientific knowledge. While these notions were of course not available to Plato, they highlight the complexity of the subject which Timaeus is addressing. ${ }^{13}$ Uncontroversially, the text alludes to the digestive and respiratory tracts, and subsequently to certain processes that occur in these. Indeed, the structure described by Timaeus can be regarded as two hollow compartments within the body which share common passages: the nose and mouth first join together in the pharynx, and then bifurcate again into the digestive and the respiratory branch of this connected system. ${ }^{\mathrm{I}}$ In modern terms, the compound structure that Timaeus is describing is comprised of the upper airway (nose, mouth, naso-pharynx, oro-pharynx and larynx), the lower airway (trachea, bronchi and lungs), and the upper digestive tract (oesophagus and stomach). ${ }^{15}$

Schematically, we conceive of the digestive apparatus as a long tube encircling a 'virtual' space (i.e. a space that only becomes a real cavity when air or food distend it), with specialised regions (organs) that fulfil different functions. The oesophagus is a thin tube that mainly transports food; the stomach is a thicker, more muscular and more dilated tube, where the nutrients are mixed and digestion begins; the bowels are comprised of different parts (duodenum, jejunum, ileum and colon), in which digestion continues and the resulting microscopic particles are absorbed into the bloodstream. Through digestion the larger molecules which constitute our nourishment are divided into smaller particles,

I3 Longrigg (I993, I35) observes, reasonably, that Plato did not have in-depth anatomical knowledge, though clearly he did have a general idea of what humans look like, which our interpretation below will have to respect.

I4 Despite some minor differences, all modern interpreters agree thus far: so e.g. Cornford (I937), Joubaud (I99I), Brisson (200I), Longrigg (I993), Zeyl (2000), Velasquez (2004), Lisi (20II).

I5 The bowels are not considered in the discussion, because Timeaus considers that absorption is carried out entirely in the stomach, and that the function of the bowels is to retain food and drink, given the insatiable nature of humans (73a). 
so that they can be absorbed by the mucosa - the surface layer of cells that coats the whole digestive tube, through which the particles proceed into the bloodstream, which then distributes them throughout the body.

The respiratory apparatus, on the other hand, is a more rigid tube (hence not delimiting a virtual space but a 'lumen' constantly full of air), which progressively branches into thinner structures: the larynx is contiguous with the trachea, which then divides into the two main bronchi. Each of these tubes branches again - as they enter the lungs - into several thinner bronchioles, which continue dividing until they reach the tiny alveolar sacks, the dead ends of the respiratory airway, where oxygen from the environment reaches the bloodstream in exchange for the waste product of the body's metabolism, carbon dioxide. Respiration (or, technically, 'ventilation') is the process by which the oxygen-rich air is carried from the nose and mouth through the 'intraluminal airway' to the alveoli, and by which carbon dioxide is transported in the opposite direction.

Timaeus therefore aims here to present his understanding of a group of organs which are contiguous with each other and with the environment, and whose function is to receive elements from outside the body, process them (digestion and respiration), and carry them into the blood (absorption and oxygenation). This endeavour poses two main challenges. The first is a problem of definition: he is characterising different organs, but they are next to each other, lack clear boundaries between them, and share a tubular structure. Contrary to Cornford's interpretation (1937, 303), Plato is not vague about the connection between the fish-trap and each of the specific organs. Although he does not distinguish as many as we currently do, he explicitly mentions the placement of the

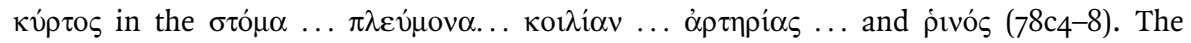
verbs $\alpha \varphi i \eta \mu 1, \mu \varepsilon \theta i \eta \mu$ and $\kappa \alpha \theta i \eta \eta$ suggest that the young gods are laying a 'functional tissue' into the organs that they previously created (70c4-73a8).

The second hurdle is to describe the relation of these organs to the exterior. The system is open to the cosmos and in constant interchange with the outside, although the organs are inside the body. This makes the use of words like 'inside' and 'outside' tricky, as one can see from modern science's counter-intuitive practice: in physiological terms anything that has not yet been absorbed into the bloodstream - even including digested food 'inside' the stomach - is considered to be 'external' to the body. As will be shown below, much of the confusion about the actual location of the components of the fish-trap and their functioning is due to such ambiguities.

For readers, one of the key difficulties of this passage is to visualise the organs described. There are two main traditions: Galen, followed by Taylor, imagined a big fish-

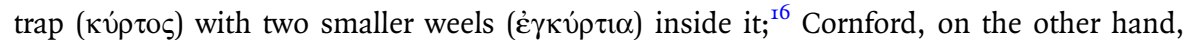

I6 Gal. In Pl. Ti. 9; Taylor (I928) 549-50. Apart from Cornford's criticism of this theory, which is mainly based on the

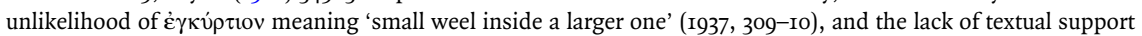
for positing three fish traps, the idea of two separate baskets is incompatible with the physiology. Timaeus constantly describes the close interaction between the processes of digestion and respiration, which would be very hard to explain if the two compartments were separate. 


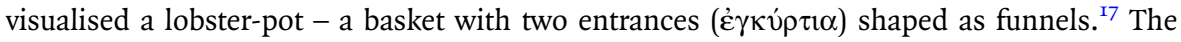
latter is the interpretation that most modern translators and commentators support, and Cornford goes to some lengths to find correspondences between the shape of the entrances to different kinds of lobster-pot and the human nose and mouth. ${ }^{18}$ However, an excessively literal adherence to the simile, which fails to see its metaphorical dimension, has several shortcomings. It is difficult to imagine such a pot inside the body, and a structure as rigid as an actual lobster-pot could hardly allow the movements

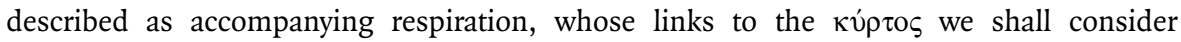
below. Furthermore, Cornford and his followers seem to be more interested in making

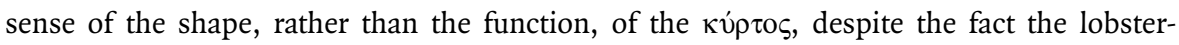
pot model, taken literally, can be hardly reconciled with an actual human body. Indeed, interpreters have focused their attentions on the shape of the entrances specifically, to the neglect of the rest of the structure.

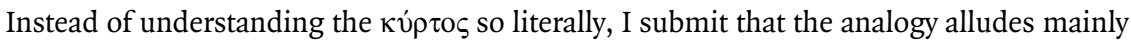

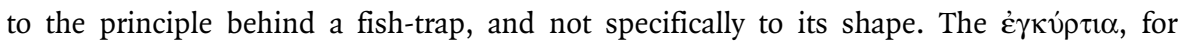

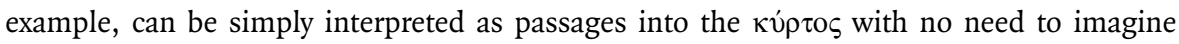
them shaped as funnels. Thus Timaeus would simply be outlining a structure with two wide entrances which allow sizeable things in but trap them once inside, since only very small particles can pass through its walls. The description would aim to account not for the organs' shape (anatomy), but for their constitution from tissues (histology), in order to explain the processes they carry out. Admittedly, as noted above, the way in which the organs divide and branch is tackled immediately afterwards $(78 \mathrm{c} 4-\mathrm{dr})$, and the fish-trap is systematically mapped onto body-parts. However this does not disprove the hypothesis that the analogy is primarily functional. Rather, it highlights Plato's comprehensive approach to the body; even nowadays it is impossible to understand histology and physiology without some basic anatomical notions.

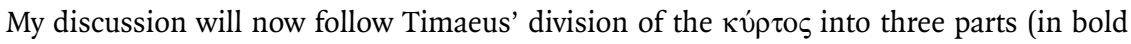

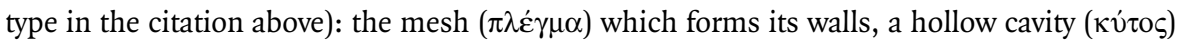

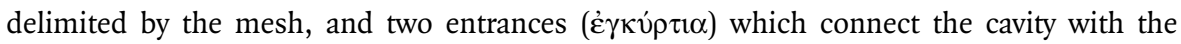
exterior. Within the description, the image of an interwoven structure is persistent:

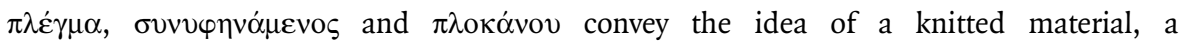
reticulated sieve which only allows the passage of the smallest particles (air and fire).

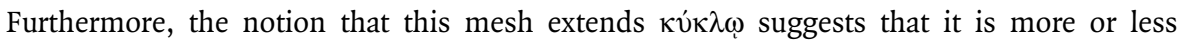
tubular. The comparison with reeds intuitively conveys an idea of a flexible structure, as opposed to a rigid lobster-pot made out of wicker lattices.

I7 Cornford (1937) 308-I2.

I8 Brisson (200I, I97) does not discuss the shape of the fish-trap, but he translates غ̇ $\gamma \kappa u ́ p \tau \imath \alpha$ as 'entonnoirs'. Zeyl (2000) maintains Cornford's 'funnels'. Neither Lisi (201I, I25) nor Velasquez $(2004,204)$ translate غ̇ $\gamma \kappa v ́ \rho \tau 1 \alpha$ as 'embudos', probably because the word is cacophonic, but they both clearly follow Cornford's interpretation. Longrigg (1993, I36-9) plots diagrams to adapt Cornford's model. 
We should imagine, therefore, this flexible net surrounding - and delimiting - a hollow

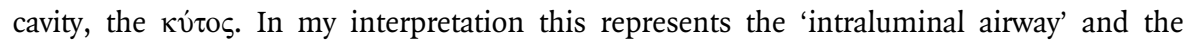
'virtual space' in the empty digestive tract. However, where exactly Timaeus locates the

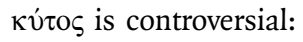

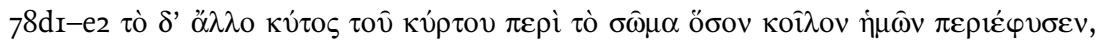

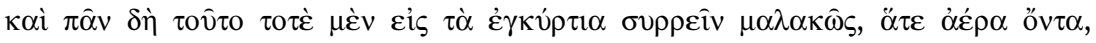

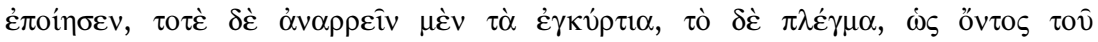

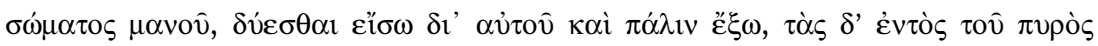

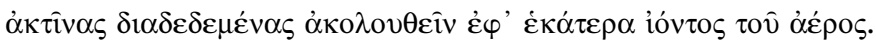

The cavity, the other part of the trap, ${ }^{19}$ he made to grow around the part of our body that is hollow. And he made all this now flow together gently towards the entrances, as they are made of air; then the entrances flow back again, and - because the body is porous - the mesh is pushed through the body towards the inside, and back again towards the outside. The inner rays of fire that are fast-bound [to the mesh], he made to accompany the air as it passed in both directions.

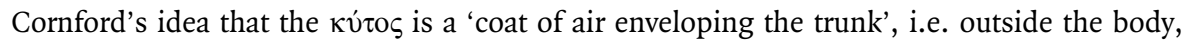
derives from Galen's interpretation that Timaeus is describing two small weels inside the bigger weel that represents the skin. ${ }^{20}$ However, it seems extremely surprising that a structure which was so far described as internal to the body $(78 \mathrm{c} 4-\mathrm{dI})$ should have a component outside the body, without an explicit clarification to that effect. It is therefore

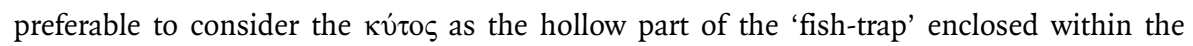
limits of the mesh, and to imagine both inside the torso. Plato has already used the preposition $\pi \varepsilon \rho$ i with the accusative to convey the idea that something is spread out within a circular space: in 77er, when describing the irrigation of the head, $\sigma \chi i \sigma \alpha v \tau \varepsilon \varsigma$ $\pi \varepsilon \rho \grave{i} \tau \grave{\eta} v \kappa \varepsilon \varphi \alpha \lambda \grave{\eta} v \tau \grave{\alpha} \varsigma \varphi \lambda \varepsilon \dot{\beta} \alpha \varsigma$ does not imply that the blood vessels surround the head externally, but that they encircle it from within. Similarly, since the $\pi \lambda \dot{\varepsilon} \gamma \mu \alpha$ is circular

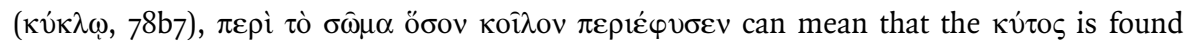
all around the internal hollow part of the body. This ambiguity is one example of the aforementioned difficulty in using words like 'internal' and 'external' with respect to the organs under discussion.

Let us visualise the structure, then, as a closely knit, flexible net which has a doubleentrance (the mouth and nose), and delimits a hollow cavity, taking the shape of the organs involved (e.g. the lungs and stomach). A further controversial issue is where to locate the elemental particles, which ultimately condition the organs' physiology. The

I9 A literal translation would be 'The rest of the cavity of the fish-trap'. This rendering tries to highlight the fact that

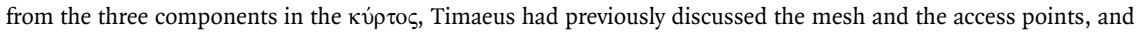
now he is going to address the third: the hollow cavity.

20 Cornford (I937) 3 I3. 
first sentence of the description is very clear: the mesh is composed of fire and air (78b4). Later, we hear that digestion is achieved through 'rays of fire' (78d6: see below). We should imagine therefore a fine net where the air occupies the space between woven 'threads' (rays)

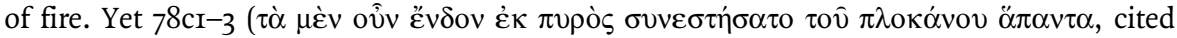
above) has led most scholars to interpret that the fire is not to be found forming the mesh, but inside the whole structure: they understand that Plato is talking about 'all the parts within the webbing'. Yet interpreting that the text refers to the 'inner parts of the structure in their entirety' is grammatically acceptable and has the distinct advantage of reconciling the passage with $78 \mathrm{~b} 4$. Furthermore, the point that threads of fire form the inner walls of the mesh explains the need for the respiratory movements to allow digestion, in the manner discussed below. If the fire was in the cavity all the time, no movement would be needed for it to process the food. Thirdly, all interpreters from Galen to modern versions place the fire inside the belly, and yet have to translate in $78 \mathrm{e} 7$ that the fire 'enters the belly'. This contradiction arises, again, because of the ambiguity about what is interior and what is exterior in relation to the body. Interpreters have failed to realise that हैvסov (78cI) is used to emphasise that the $\pi \lambda \dot{\varepsilon} \gamma \mu \alpha$ is innermost, when

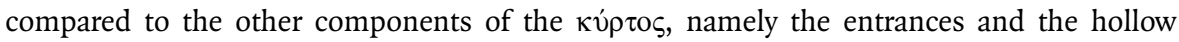
cavity which are mentioned immediately afterwards. Such components are completely open and contiguous with the outside world. Furthermore, they are both made of air that is constantly entering and exiting the body; thus, they are perceived as being more external than the mesh, whose fire is described as being ëvoov.

In summary, Plato's use of the fish-trap simile is not actually meant to illustrate the shape of this structure, but primarily the mesh-like characteristics of its walls. ${ }^{2 I}$ The

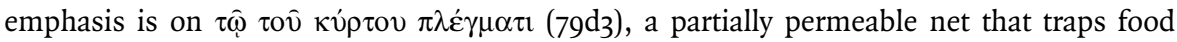
and drink (78a7) and only allows fire and air to pass. Indeed, this emphasis is reinforced by the fact that the whole account is preceded by the enunciation of a law of movement, whereby smaller particles can penetrate between larger ones and not vice versa.

\section{Digestion, absorption, formation of blood, nutrition}

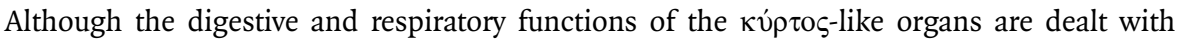
separately, in Timaeus' conception these processes are closely related and interdependent. The accounts of them, therefore, sometimes overlap. This is why the discussion of digestion is preceded by a brief explanation of the movement of air, for which a fuller account (discussed in the next section) comes later: for Timaeus, the flux of air is crucial for understanding digestion.

In this regard it is important to highlight that, since I visualise the kv́to inside the body, my whole understanding of the discussion of the movement of air is opposed to Cornford's.

2I As in Hippocratic treatises, similes and analogies are used to illustrate ideas and conepts that may not be easily grasped only with an explanation (Craik 200I, II3). 
First of all, note that in $78 \mathrm{~d} \mathrm{I}-4$ Timaeus is not actually talking about the movement of the

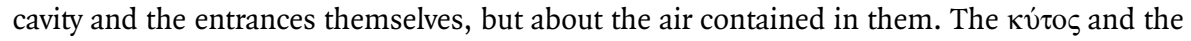

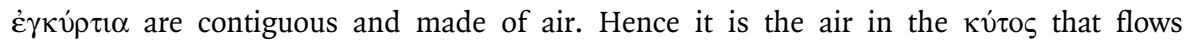

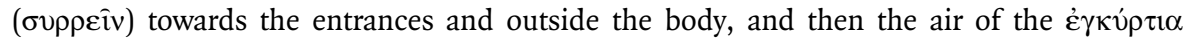

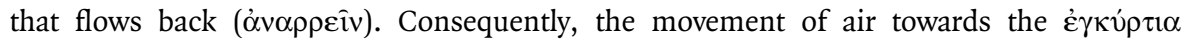

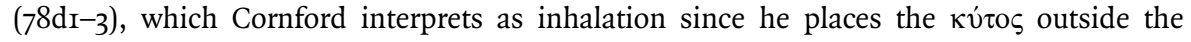
body, is in my interpretation rather the movement of the air contained in the hollow cavity inside the body (the lungs in this case) towards the upper airway and the exterior, i.e. exhalation. ${ }^{22}$ In this way (unlike on Cornford's account) the brief outline of respiration matches the later and more detailed account, where again exhalation precedes inhalation.

To visualise the process we should bear in mind that Timaeus denied the existence of void, and that - as argued above - the walls of the stomach and the lungs are made of the fire mesh. Consequently, after exhalation, the air expelled from the lungs pushes progressively the surrounding air, until it eventually enters through the body, i.e. through the pores of the skin $\left(78 \mathrm{~d}_{4}\right)$. The most interesting theory about these pores was proposed by Joubaud, ${ }^{23}$ who imagined them as subcutaneous 'vies gaseuses invisibles' distributed

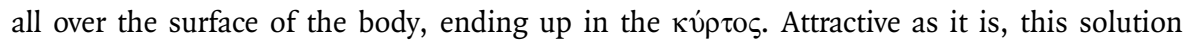
poses some problems: why does the air need to change its direction in inhalation and exhalation? Why can it not simply pass circularly from the pores to the fish-trap then to the environement and subsequently back to the pores? In other words, why does it need instead to exit the body again through the pores? Moreover, how can the fire in the mesh follow or be moved by this air-flow, as is later described in $78 \mathrm{e} 6$ ? We should, as Joubaud does, imagine the subcutaneous airway as an imperceptible system of ducts stretching from the skin centripetally, through the thickness of the body towards its centre where

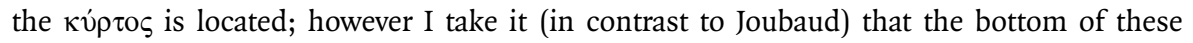

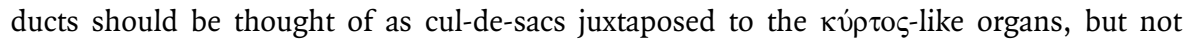
contiguous with them, and that the ducts swell when filled with air. Thus, during exhalation, when the air is moved by $\pi \varepsilon p i \omega \sigma ı \varsigma$ towards the pores, their dead ends swell,

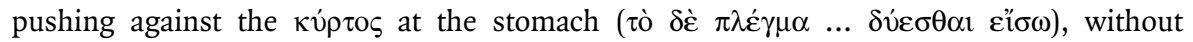
allowing the passage of air. This pressure enables contact between the rays of fire in the mesh-like walls of the stomach, and the food and drink which have entered through one

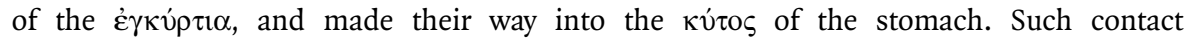
eventually leads to the digestion of nourishment and to the transference of small digested particles through the mesh towards the blood vessels. Subsequently, inhalation sucks the

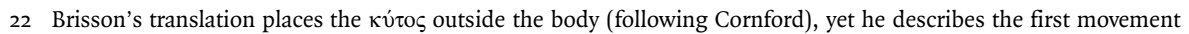
as exhalation, claiming that Timaeus is talking about the movement of the thoracic cage rather than the movement of air (200I, I97 n. 686). Although this interpretation is not sustained by the text, the fact that he alludes to the thoracic cage shows that Brisson could also intuit the ambiguity between internal/external that creates the confusion in this passage.

23 Joubaud (I99I) 67. 
air that had entered through the skin outwards again by $\pi \varepsilon \rho i \omega \sigma ı \varsigma$ (because there is no void). This movement of air, from the dead end of the skin pores through the flesh towards the

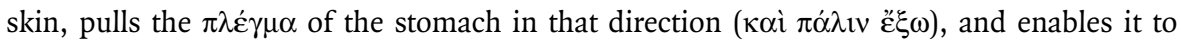
stretch.

Once these movements are established, digestion and absorption can be easily understood:

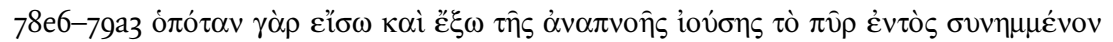

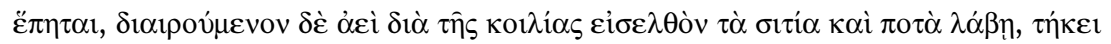

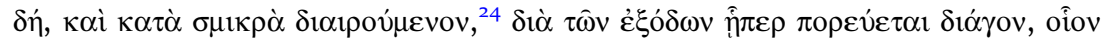

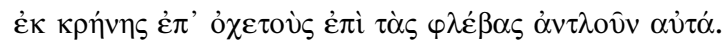

For whenever the fire, internally united with the breath, follows it as it passes in and out, and by moving inwards through the belly it constantly takes hold of and carves the food and drink, it dissolves them and, breaking them up into tiny parts, drives them through the outbound passages in the direction of its advance. It then transfers them into the blood vessels, as water from a spring is transferred into pipes.

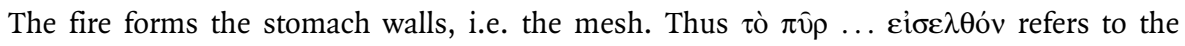
inward movement of the mesh of fire, pushed by (and hence 'accompanying') the air that has entered through the skin pores due to exhalation. This inward movement facilitates contact between the rays of fire within the stomach walls and the food and drink inside its cavity, which are thereby split (digested). ${ }^{25}$

As stated, the sharp particles of fire and the air present in the mesh are kept in oscillation by the alternating movement of air. Here again, the notions of inwards and outwards become confusing, because the point of reference has changed. Previously, as I argued above regarding $78 \mathrm{cI}-3$, Timaeus had described the mesh as being inner in relation to the cavity, because the latter was made of air contiguous with air from the environment. Now the reference-point is the skin with its pores, compared to which the

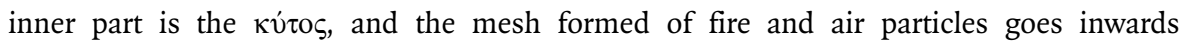

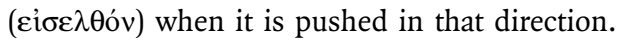

At this point Timaeus returns to the image of gardening and irrigation, and $\tau \grave{\alpha} \tau \hat{\omega} v$ $\varphi \lambda \varepsilon \beta \hat{\omega} v \dot{\rho} \varepsilon \dot{\mu} \mu \alpha \tau \alpha$ (79a3) become $\tau \dot{\alpha} \tau \hat{\eta} \varsigma \tau \rho \circ \varphi \hat{\eta} \varsigma$ vó $\mu \alpha \tau \alpha$ (8od7). The processes described before are completed with the formation of blood (8odI-e7), which is the 'nutrient for

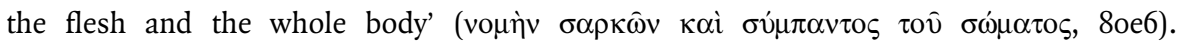
Moreover, we are reminded that the blood is formed from fruit and vegetables (8od8-er),

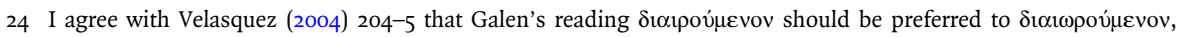
because of the sense, and because the former is fairly common in Plato whereas the latter would be a hapax.

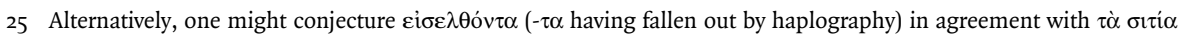

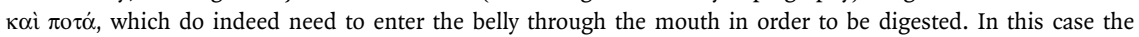
translation would be 'the fire ... takes hold of the food and drink that have made their way into the belly'. 
which underlines the circular flow of substances between the macrocosm and the microcosm discussed in what I earlier termed the 'environmental' ring surrounding this section of the dialogue.

\section{Respiration}

Interpreters generally agree that the account of respiration is mechanistic and based on two

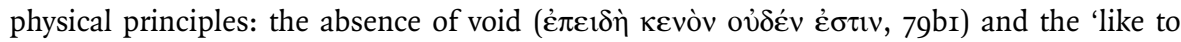

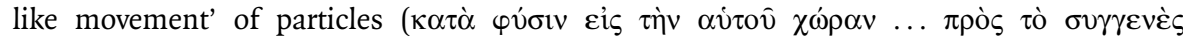

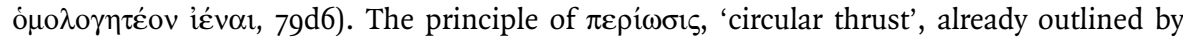
Timaeus in order to explain digestion, is here discussed in more depth.

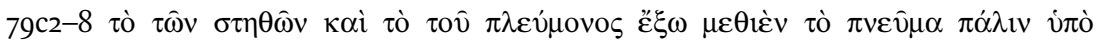

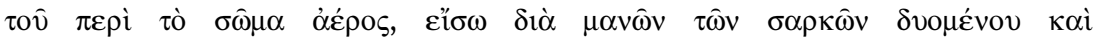

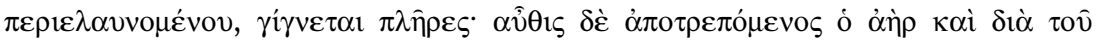

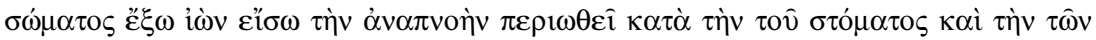

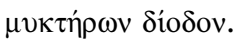

While releasing the breath outwards, the area of the chest and the lungs is filled up again by the air that surrounds the body, which is pushed circularly and penetrates the porous flesh. When in turn the air is turned back and passes outwards through the body, it thrusts the inhaled air around, back inwards through the passage of the mouth and nostrils.

My visualisation of the system explains some of this mechanism more convincingly than that of other scholars. By imagining the pores of the skin as subcutaneous air-ducts with a distensible dead end, it is clear why there is no interchange of air between the lungs and the skin - an issue which puzzled both Taylor and Cornford. ${ }^{26}$ In this closed system without void, as Joubaud has remarked, the 'cutaneous respiration' is an intermediate deposit of air between the inspiration and expiration phases of 'lung respiration'. ${ }^{27}$ Undoubtedly, Timaeus implies that both types of respiration fill the thorax and the lungs. The advantage of my interpretation is that 'lung respiration' fills the lungs from within, through the airway, whereas 'cutaneous respiration' fills the thorax from without, through the skin pores. Otherwise, as pointed out above, if the pores were permeable to air, its particles would enter the lungs through the skin and the movement would be continuous, perpetual and circular, without the need for inspiration and expiration.

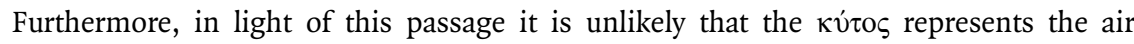

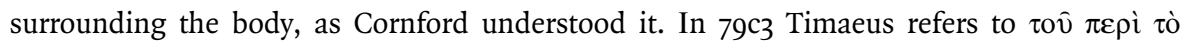

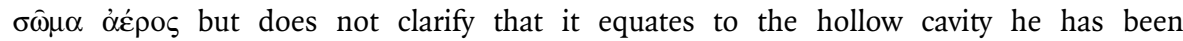


mentioning, whereas elsewhere in this section he does make such clarifications, for example about how 'inner heat' relates to the earlier fish-trap simile:

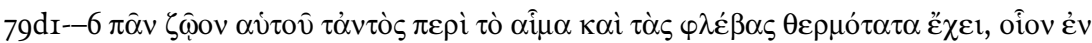

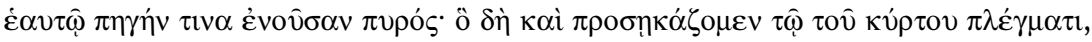

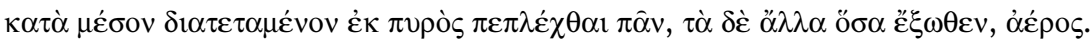

In every living creature, the inner parts - those that are close to the blood and the blood vessels - are its hottest, like a spring of fire inside it. It was, indeed, this that we compared to the mesh of the fish-trap: it is entirely woven of fire, we said, and extended throughout the middle, whereas the rest, that which comes from the outside, is made of air.

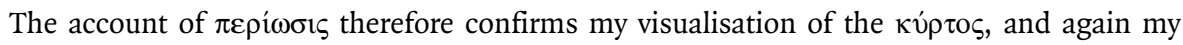
model explains some difficulties which previous interpretations could not resolve. The passage just cited describes very clearly that what corresponds to the mesh of the fish-

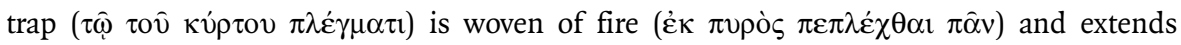

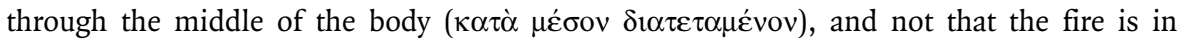
the middle of the kviros. In this regard, the main problem with Cornford's translation is that it is completely unconnected with the previous description of the fish-trap. ${ }^{28}$ In his explanation of this passage he focuses on the rationale of $\pi \varepsilon p i \omega \sigma t \varsigma$ but he does not

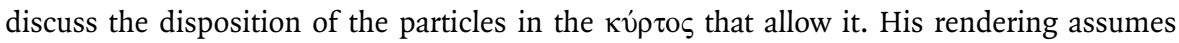
that the $\pi \lambda \dot{\varepsilon} \gamma \mu \alpha$ is comprised of two parts, which had not been mentioned before, and that outside one of these parts there is air. Still, it is not clear where exactly: outside the $\pi \lambda \dot{\varepsilon} \gamma \mu \alpha$ but inside the body, i.e. between the $\pi \lambda \dot{\varepsilon} \gamma \mu \alpha$ and the skin, or completely outside the body? In other words, Cornford is interested in making sense of the process, but he does not try to make it compatible with his model of the lobster-pot. Therefore, it is

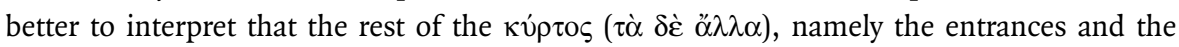
hollow cavity (and not the rest of the $\pi \lambda \dot{\varepsilon} \gamma \mu \alpha$ ), are made of air that comes from the outside ( $(\varepsilon \omega \theta \varepsilon v)$. Once again, the difficulty originates in the confusion between what is internal and what is external to the body. Consequently, Cornford and all modern interpreters translate $\check{\varepsilon} \xi \omega \theta \varepsilon v$ simply as 'external' (instead of as 'coming from the outside', which is the primary meaning). Finally, by interpreting the fire as part of the mesh that surrounds the lungs and stomach, it is easier to understand how it heats the air, and to visualise its closeness to the blood and the blood vessels.

In summary, the present analysis offers an alternative model to Cornford's standard view

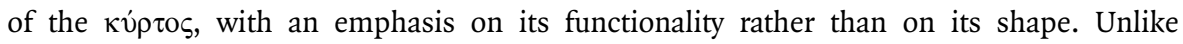
available interpretations, it explains more accurately the location of the particles within the structure, their movements and their interaction and, thus, the rationale for the 
physiological processes in which they participate. Meanwhile I have provided an image more in line with bodily anatomy.

Additionally, my discussion of ring-composition exposes how Timaeus conceives the interaction between humans and the cosmos. Timaeus presents human physiology as a system of concentric processes: irrigation is the most peripheral one, which drives the nourishment right up to the surface of the body. Subsequently, digestion and absorption occupy an intermediate position between what is received from the cosmos, and what is taken centrifugally to the rest of the body by the 'water-pipes'. Finally in the centre of both the narrative and the processes is respiration, the innermost mechanism that enables the others. This account proceeds from the periphery to the centre, whereas the actual progression of substances through the body occurs in the opposite direction: the

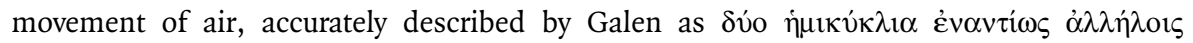
кıvoú $\mu \varepsilon v \alpha,{ }^{29}$ enables the oscillatory movement of fire particles in the mesh, which in turn digest the food, which is then absorbed into the blood vessels and turned into blood. Subsequently, this blood is conducted centrifugally through the irrigation system, to replenish $(\pi \lambda \eta \rho o \hat{)})$ what is constantly being wasted away by the environment ( $\tau \dot{\alpha} \mu \grave{\varepsilon} v$

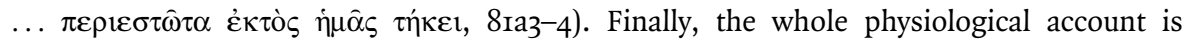
framed within a ring describing the circular flux of elements from the macrocosm through the body and back to the environment. ${ }^{30}$ The ring-composition of the discourse thus reproduces the concentric nature of the processes described, so that Timaeus is creating an image modelled on the reality that he is actually describing: ${ }^{3 \mathrm{I}}$ indeed, he earlier defined such images in terms of 'words having affinity to the very things they explain' ( Moreover, the account assimilates the human body to the dialogue's recurrent uses of a circular model. In the account of creation, Osborne has convincingly demonstrated a correspondence between three circular returns to the beginning, and the arrangement of the circles of the Same and the Different in the construction of the world-soul. ${ }^{32}$ In this way, the body is connected to the cosmos not only through the circular flux of substances, but also through the very circularity of its conception. Ultimately, in the context of Timaeus' teleological cosmogony, this account illustrates how humans are an integral part of the cosmos, in continuous interaction with it.

29 Galen, In Pl. Ti. I9. The first hemicycle, on my account, represents exhalation, whereby the air contained in the

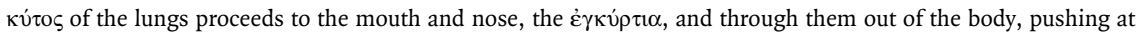
the same time the air surrounding the body which in turn enters the pores of the skin. Inside the pores, the air continues its route all the way down until it swells the dead ends of the pores, which in turn push the $\pi \lambda \dot{\varepsilon} \gamma \mu \alpha$ of the stomach. The second hemicycle corresponds to inspiration, in which the air follows the exact opposite direction.

30 Miller (1957) ro6-8.

$3 \mathrm{I} \quad$ Osborne (2000) I88-9.

32 Osborne (2000) I97. 


\section{Works Cited}

Ayache, L. (1997) 'Est-il vraiment question d'art médical dans le Timée?' in T. Calvo and L. Brisson (eds.) Interpreting the Timaeus-Critias: proceedings of the IV Symposium Platonicum, Granada, 55-63.

Brisson, L. (ed.) (200I) Platon: Timée, Critias. Translation, introduction and notes, 5 th edn, Paris.

Broadie, S. (2012) Nature and divinity in Plato's Timaeus, Cambridge.

Cornford, F. M. (1937) Plato's cosmology: the Timaeus of Plato, London.

Craik, E. M. (200I) 'Plato and medical texts: Symposium I85c-I93d', CQ 5I(I), Io9-I4.

Harris, C. R. S. (I973) The heart and the vascular system in ancient Greek medicine, from Alcmaeon to Galen, Oxford.

Hershbell, J. P. (1974) 'Empedoclean influences on the Timaeus', Phoenix 28(2), 145-66.

Johansen, T. K. (2004) Plato's natural philosophy: a study of the Timaeus-Critias, Cambridge.

Joubaud, C. (I99I) Le corps humain dans la philosophie platonicienne: étude à partir du Timée, Paris.

Karasmanis, V. (2005) 'ANAГKH and NOr 2 : the method of biological research in the Timaeus', Rhizai 2(2), I67-82.

Larrain, C. J (ed.) (1992) In Platonis Timaeum comentarii, Galens Kommentar zu Platons Timaios, Stuttgart.

Lisi, F. (20II) Platón: Timeo, Madrid.

Longrigg, A. (1993) Greek rational medicine: philosophy and medicine from Alcmaeon to the Alexandrians, New York.

Miller, H. W. (I957) 'The flux of the body in Plato's Timaeus', TAPhA 88, I03-I3

Mohr, R. D. (2010) 'Plato's cosmic manual: introduction, reader's guide, and acknowledgments', in Mohr and Sattler (2010), I-27.

Mohr, R. D. and Sattler, B. M. (eds.) (2010) One book, the whole universe: Plato's Timaeus today, Las Vegas. Mugler, C. (1958) 'Alcméon et les cycles physiologiques de Platon', REG 7I, 42-50.

O’Brien, D. (1970) 'The effect of a simile: Empedocles' theories of seeing and breathing', JHS 90, I40-79.

Osborne, C. (2000) 'Space, time, shape and direction: creative discourse in the Timaeus', In C. Gill, M. M. McCabe (eds.) Form and argument in late Plato, Oxford, I79-2II.

Rivaud, A. R. (I970) Platon: Timée. Critias, Budé, Paris.

Sedley, D. (2010) 'Hesiod's Theogony and Plato's Timaeus', In G. R. Boys-Stones, J. H. Haubold (eds.) Plato and Hesiod, Oxford.

Taylor, A. E. (I928) A commentary on Plato's Timaeus, Oxford.

Velasquez, O. (ed.) (2004) Platon, Timeo: traducción y notas, Santiago, Chile.

Zeyl, D. (2000) Plato: Timaeus, Cambridge, MA.

(2010) 'Visualizing Platonic space', in Mohr and Sattler (2010), II7-30. 